\title{
Interactions between the NR2B Receptor and CaMKII Modulate Synaptic Plasticity and Spatial Learning
}

\author{
Yu Zhou, ${ }^{1,2,3,4}$ Eiki Takahashi, ${ }^{1,2,3,4}$ Weidong Li, ${ }^{1,2,3,4}$ Amy Halt, ${ }^{6}$ Brian Wiltgen, ${ }^{1,2,3,4}$ Dan Ehninger, ${ }^{1,2,3,4}$ Guo-Dong Li, ${ }^{5}$ \\ Johannes W. Hell, ${ }^{6}$ Mary B. Kennedy, ${ }^{7}$ and Alcino J. Silva ${ }^{1,2,3,4}$ \\ ${ }^{1}$ Department of Neurobiology, ${ }^{2}$ Semel Institute, ${ }^{3}$ Department of Psychology, ${ }^{4}$ Brain Research Institute, and ${ }^{5}$ Department of Molecular and Medical \\ Pharmacology, Geffen School of Medicine, University of California, Los Angeles, Los Angeles, California 90095-1761, ${ }^{6}$ Department of Pharmacology, Roy J. \\ and Lucille A. Carver College of Medicine, University of Iowa, Iowa City, Iowa 52242-1109, and 7Division of Biology 216-76, California Institute of \\ Technology, Pasadena, California 91125
}

The NR2B subunit of the NMDA receptor interacts with several prominent proteins in the postsynaptic density, including calcium/ calmodulin-dependent protein kinase II (CaMKII). To determine the function of these interactions, we derived transgenic mice expressing a ligand-activated carboxy-terminal NR2B fragment (cNR2B) by fusing this fragment to a tamoxifen (TAM)-dependent mutant of the estrogen receptor ligand-binding domain $\mathrm{LBD}^{\mathrm{G} 521 \mathrm{R}}$. Here, we show that induction by TAM allows the transgenic cNR2B fragment to bind to endogenous CaMKII in neurons. Activation of the $\mathrm{LBD}^{\mathrm{G} 521 \mathrm{R}}$-cNR2B transgenic protein in mice leads to the disruption of CaMKII/NR2B interactions at synapses. The disruption decreases Thr286 phosphorylation of $\alpha$ CaMKII, lowers phosphorylation of a key CaMKII substrate in the postsynaptic membrane (AMPA receptor subunit glutamate receptor 1), and produces deficits in hippocampal long-term potentiation and spatial learning. Together our results demonstrate the importance of interactions between CaMKII and NR2B for CaMKII activity, synaptic plasticity, and learning.

Key words: CaMKII; NMDA receptor; synapse; plasticity; learning; memory

\section{Introduction}

NMDA receptors (NMDARs) are heteromeric complexes containing both NR1 and NR2 subunits (Cull-Candy et al., 2001), and more rarely NR3 subunits (Prybylowski and Wenthold, 2004). The NR2 subunits (NR2A-2D) are encoded by four distinct genes. NR2A and NR2B subunits are the predominant NR2 subunits in adult hippocampus and neocortex (Monyer et al., 1994).

Mutations of NR2A and NR2B indicate that both are important for plasticity and memory performance in adult mice (Sakimura et al., 1995; Kiyama et al., 1998; Kohr et al., 2003). Consistently, previous pharmacological studies, including in vivo recordings, showed that NR2A and NR2B subunits are critical for the expression of long-term potentiation (LTP) in hippocampal and cortical regions (Berberich et al., 2005; Weitlauf et al., 2005; Fox et al., 2006). In addition, overexpression of the NR2B subunit in the hippocampus increases the amplitude of LTP in the CA1 region and enhances learning (Tang et al., 1999). Pharmacological blockade of the NR2B subunit has also been shown to impair

\footnotetext{
Received July 30, 2007; revised 0ct. 25, 2007; accepted 0ct. 25, 2007.

This work was supported by National Institutes of Health Grant 98-069-23 (A.J.S.). We thank Robert A. M. Brown and Anna Matynia for critical discussions and helpful comments, and Edoardo Dado Marcora and Tinh Luong for expert technical assistance.

Correspondence should be addressed to Alcino J. Silva, Department of Neurobiology, University of California, Los Angeles, Los Angeles, California 90095-1761. E-mail: silvaa@mednet.ucla.edu.

E. Takahashi's present address: Research Resources Center, RIKEN Brain Science Institute, 2-1 Hirosawa, Wako, Saitama, 351-0198 Japan.

D01:10.1523/JNEUROSCI.4486-07.2007

Copyright $\odot 2007$ Society for Neuroscience $\quad$ 0270-6474/07/2713843-11\$15.00/0
}

fear learning in the anterior cingulate cortex and the amygdala (Rodrigues et al., 2001; Zhao et al., 2005). These latter findings suggest that the NR2B subunit is particularly important for plasticity and learning. The goal of the current study was to determine the signaling pathways through which the NR2B subunit affects these processes.

There are multiple downstream signaling pathways linked to the NMDARs that may play important roles in plasticity and memory (Thomas and Huganir, 2004; Barria and Malinow, 2005; Kennedy et al., 2005; Kim et al., 2005). Several important postsynaptic density (PSD) proteins, including calcium/ calmodulin-dependent protein kinase II (CaMKII) and PSD-95 are known to interact with NR2B in vitro, but little is known about how these interactions influence their functions (Kornau et al., 1995; Leonard et al., 1999; Kennedy, 2000). Interactions with CaMKII are particularly interesting because of its well established role in plasticity and learning (Silva et al., 1992; Mayford et al., 1996) and also because of its high-affinity binding to the C-terminal tail of the NR2B subunit (Strack and Colbran, 1998; Leonard et al., 1999; Strack et al., 2000). Previous studies suggested that NR2B binding targets active CaMKII to signaling networks in the postsynaptic density and supports persistent activity of this kinase in specific subcellular compartments (Bayer et al., 2001; Robison et al., 2005a,b). Given that introduction of persistently active CaMKII into neurons produces LTP at synapses (Pettit et al., 1994; Lledo et al., 1995), the association between NR2B and active CaMKII could be a key component mediating synaptic plasticity and certain types of learning (Lisman et al., 
2002). Consistent with this idea, previous studies from organotypic hippocampal slices ( $7-8 \mathrm{~d}$ in culture) demonstrated that the association between NR2B and active CaMKII is required for LTP (Barria and Malinow, 2005). However, the precise physiological role of the association between NR2B and active CaMKII, as well as the association between NR2B and other synaptic proteins in adult animals has not been elucidated. Nor has it been shown whether these associations with NR2B are important for learning and memory at the systems level.

The current study addresses this issue by demonstrating that inducible and reversible disruption of NR2B/CaMKII interactions in transgenic mice downregulates Thr286 phosphorylation of $\alpha$ CaMKII, disrupts LTP in the hippocampus, and impairs spatial learning.

\section{Materials and Methods}

Transgene construction and generation of $c$ NR2B mice. The transgene used in these studies contains an $\alpha$ CaMKII promoter, a hybrid intron in the $5^{\prime}$ untranslated leader, a Kozak sequence, a hemiagglutinin virus (HA)-tag, an LBD ${ }^{\mathrm{G} 521 \mathrm{R}} \mathrm{cDNA}$, and a polyadenylation signal (Kida et al. 2002). The coding region of the NR2B c terminus ( $839-1482$ aa) was subcloned into the pMM-LBD ${ }^{\text {G521R }}$-CREB ${ }^{\mathrm{S} 133 \mathrm{~A}}$ vector; we used PCR and restriction enzymes to replace the $C R E B^{S 133 A}$ gene by the NR2B c terminus gene, resulting in the pNN-LBD ${ }^{\mathrm{G} 21 \mathrm{R}}$-NR2B plasmid. The NR2B cDNA (1$1482 \mathrm{aa}$ ) clone was kindly provided by Dr. Gary Lynch (University of

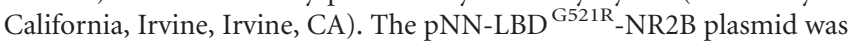
digested with SfiI, and transgenic mice were generated by injecting the purified insert into pronuclei of C57BL/6NHsd zygotes. Studies were performed in F1 mice (aged 3-6 months) that were offspring of a cross between the founders and C57BL/6N (TacF) mice (Taconic Farms, Germantown, NY). All experiments were performed blind with respect to genotype and treatment. All animal protocols were approved by the Chancellor's Animal Research Committee at the University of California at Los Angeles, in accordance with National Institutes of Health guidelines.

$R T$-PCR. Hippocampus and cortex were acutely dissociated from mouse brains. Total RNA ( $1 \mu \mathrm{g})$ was reverse-transcribed with an oligo $\mathrm{dT}$ primer. The PCRs were performed for 35 cycles (a 1 min cycle at each of the following temperatures: 94,56 , and $72^{\circ} \mathrm{C}$ ). PCR products were

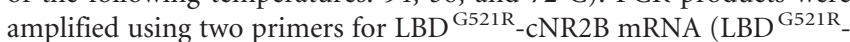
cNR2B, 5' -ATT CGC TGT CTG CGA GGG CC, and LBD ${ }^{\text {G521R }}$-cNR2B, $3^{\prime}$-TCA TGG AGG GTC AAA TCC AC). The transgene for $\mathrm{LBD}^{\mathrm{G} 521 \mathrm{R}_{-}}$ cNR2B contains an intron (235 bp) in the region between sequences corresponding to $5^{\prime}$ and $3^{\prime}$ ends, such that the PCR product from $\mathrm{LBD}^{\mathrm{G} 521 \mathrm{R}}-\mathrm{cNR} 2 \mathrm{~B}$ mRNA is distinct from transgene. The PCR products were analyzed by agarose gel electrophoresis and then stained by ethidium bromide.

Tamoxifen solution and pellet. Because of the extended nature of behavior studies (see below), tamoxifen citrate (TAM; Sigma, St. Louis, MO) was administered orally as pellets, whereas in other less-extended studies, TAM [in dimethyl sulfoxide (DMSO)] was injected. Pellets for oral administration were prepared by mixing TAM powder with melted peanut butter chips (H. B. Reese Candy, Hershey, PA). The mixture was molded into $200 \mathrm{mg}$ pellets containing $0.6 \mathrm{mg}$ TAM each. The TAM pellets were fed to mice once daily for $5 \mathrm{~d}$ before training and continuously during training and testing. All behavioral studies were performed using adult male mice (aged 4-6 months). In other studies (i.e., biochemical studies), TAM solution $(20 \mathrm{mg} / \mathrm{ml})$ was injected intraperitoneally daily ( $20 \mathrm{mg} / \mathrm{kg}$ body weight) for $5 \mathrm{~d}$ and mice were killed on the fifth day, $6 \mathrm{~h}$ after the final injection.

Protein isolation. PSD-enriched fractions were prepared from adult mice (3 to 4 months old) with a protocol modified from Dunkley et al. (1988). In brief, the forebrain was rapidly dissected and homogenized in ice-cold homogenization buffer (containing $4 \mathrm{~mm}$ HEPES-NaOH, $\mathrm{pH}$ 7.4, $0.32 \mathrm{M}$ sucrose, fresh protease inhibitor mixture, and optional phosphatase inhibitor mixtures; Roche, Welwyn Garden City, UK). Supernatant (S1) was collected after centrifugation of homogenates $(1000 \times g$ for
$10 \mathrm{~min}$ at $4^{\circ} \mathrm{C}$ ). S1 was diluted with the same volume of $10 \%$ Percoll (GE Healthcare Bio-Sciences, Piscataway, NJ) and then laid on top of a 10 and $20 \%$ discontinuous Percoll gradient. The interface between 10 and $20 \%$ Percoll was collected after centrifugation $\left(33,000 \times g\right.$ for 5 min at $\left.4^{\circ} \mathrm{C}\right)$ and then diluted with PSD buffer (PSDB; containing 40 mM HEPES$\mathrm{NaOH}, \mathrm{pH} 8.1$, fresh protease inhibitor mixture, and optional phosphatase inhibitor mixtures). After centrifugation at 20,000 $\times g(20 \mathrm{~min}$ at $4^{\circ} \mathrm{C}$ ), the pellet [synaptosome (SS)] was resuspended thoroughly in PSDB. Then, $0.5 \%$ Triton X-100 was added to SS lysates to enhance solubilization. After stirring for $15 \mathrm{~min}\left(4^{\circ} \mathrm{C}\right)$ and centrifugation for 40 $\min \left(40,000 \times g\right.$ at $\left.4^{\circ} \mathrm{C}\right)$, the final pellet (PSD) was resuspended in $100 \mu \mathrm{l}$ of PSDB and stored at $-80^{\circ} \mathrm{C}$ for use. A small amount of SS and S1 were also saved for additional analysis during preparation of the PSD fraction. Protein concentrations were determined by the method used by Bradford (1976) using a Bio-Rad (Hercules, CA) Protein Assay Kit.

Coimmunoprecipitation. Freshly purified synaptosome lysates (400 $\mu \mathrm{g}$ for each immunoprecipitation) were solubilized in $500 \mu \mathrm{l} 1 \%$ deoxycholate (Doc) buffer ( $\mathrm{pH} 8.5$, containing 1\% deoxycholate, $50 \mathrm{~mm}$ Tris$\mathrm{Cl}, 10$ mм EGTA, $10 \mathrm{~mm}$ EDTA, $137 \mathrm{~mm} \mathrm{NaCl}$, protease inhibitor cocktails) for $30 \mathrm{~min}$ at $37^{\circ} \mathrm{C}$, and then for $30 \mathrm{~min}$ on ice with occasional mixing. After centrifugation at $15,000 \times g$ for $10 \mathrm{~min}\left(4^{\circ} \mathrm{C}\right)$, the supernatants were saved for immunoprecipitation and subsequent immunoblotting. All steps were performed at $4^{\circ} \mathrm{C}$.

For each immunoprecipitation (IP), $500 \mu \mathrm{l}$ of PBSA (0.1\% BSA in PBS, ph 7.4) and $5 \mu \mathrm{g}$ of specific antibody were added first to prewashed Dynabeads (protein G beads, $30 \mu \mathrm{l}$; or anti-mouse IgG beads, $60 \mu \mathrm{l}$; Invitrogen, Eugene, OR). Five micrograms of mouse or rabbit IgG were used instead of the specific experimental antibody in parallel as a negative control for the IP. After incubation for $1 \mathrm{~h}$ at $4^{\circ} \mathrm{C}$, beads were washed to remove unbound antibody. Five hundred microliter $(400 \mu \mathrm{g})$ supernatants of synaptosomal lysates were then added to the beads and incubated for $3 \mathrm{~h}$ at $4^{\circ} \mathrm{C}$ with stirring. Beads were washed three times and collected on Magnet (Bio-Rad), then eluted in $1 \times$ SDS sample buffer and analyzed by Western blot. Thirty micrograms of SS lysate were eluted simultaneously as a positive control (input) for IP.

Western blotting and protein expression analysis. Protein samples were separated by electrophoresis on a 7\% SDS-PAGE gel (Bio-Rad). Gels were blotted to nitrocellulose membranes and then blocked for $1 \mathrm{~h}$ at room temperature with Tris-buffered saline containing $0.1 \%(\mathrm{v} / \mathrm{v})$ Tween 20 and 5\% (w/v) nonfat dry milk (TBST). After washing in TBST, membranes were hybridized at room temperature with antibodies of interest diluted in the blocking solution. The membranes were then incubated with IRDye-conjugated anti-mouse or anti-goat IgG $(1: 100,000)$. Protein signals were visualized and quantified with the Odyssey Imaging System (LI-COR Biosciences, Bad Homburg, Germany), which images fluorescence in two channels recording a 16-bit grayscale. Protein bands were boxed, and the integrated intensity of all the pixels within that band was calculated above average background levels of a box of the same size. Membranes were stripped in stripping buffer and reprobed with other antibodies, and finally reprobed with $\beta$-actin as a control for protein loading. The amount of phosphorylated protein was expressed as a ratio of (phosphorylated protein)/actin or (phosphorylated protein)/(total protein). The ratio of the wild-type treated with vehicle (wt/veh) group was used as a standard and other groups were normalized to it before statistical analysis. To make weak bands easier to see in some of our figures, we adjusted the contrast and brightness so that some other bands may appear saturated. However, this manipulation did not affect the quantification results because quantification was performed under linear conditions on the initial 16-bit images without background modification.

Western blots were probed with antibodies against human estrogen receptor (ER; HC-20, 1:200; Santa Cruz Biotechnology, Santa Cruz, CA), NR2BC (c terminus, 1:10,000, Xandria; prepared in the Kennedy laboratory), NR2B N terminus (NR2BN, 1:2000; prepared in the Kennedy laboratory), NR2A (1:5000, Eve; prepared in the Kennedy laboratory), NR1 (1:5000; ABR), SynGAP (1:2000; Affinity Bioreagents, Golden, CO), PSD-95 (7E3, 1:5000; Millipore, Temecula, CA), Densin-180 (CT245, c terminus; prepared in the Kennedy laboratory, 1:5,000), synaptophysin (1:2000, Millipore), Thr286-P-CaMKII (22B1, 1:1000; Affin- 
ity Bioreagents, Golden, CO), CaMKII (6G9, 1:5000 1:10,000; Millipore), $\beta$-actin (AC-15, 1:5000; Sigma), Ser831-P-GluR1 (1:50; from the Hell laboratory), and glutamate receptor 1 (GluR1; 1:1000; from the Hell laboratory), respectively.

Chemical LTP and Western blot analysis on hippocampal CA1. Sagittal hippocampal slices ( $400 \mu \mathrm{m}$ thick) were prepared from adult mice (3 to 4 months old). Slices recovered in artificial CSF (ACSF; containing $1 \mu \mathrm{M}$ 4-hydroxytomaxifen or vehicle) at room temperature for at least $1 \mathrm{~h}$ before the start of recordings. Stable baseline field EPSPs (fEPSPs) were recorded for at least $10 \mathrm{~min}$. Chemical LTP (cLTP) was subsequently induced by chemical treatment consisting of a $5 \mathrm{~min}$ application of a high $\mathrm{K}^{+} / \mathrm{Ca}^{2+} \operatorname{ACSF}\left(30 \mathrm{~mm} \mathrm{KCl}, 10 \mathrm{~mm} \mathrm{CaCl}_{2}\right.$, and $0 \mathrm{~mm} \mathrm{MgSO}_{4}$ ) preceded by $50 \mu \mathrm{M}$ forskolin (FSK) in the absence of electrical presynaptic fiber stimulation (Makhinson et al., 1999). Test stimulation and normal ACSF were applied right after perfusion with high $\mathrm{K}^{+} / \mathrm{Ca}^{2+}$ ACSF. Field EPSPs recorded at least $50 \mathrm{~min}$ after chemical treatments were compared with those measured before treatment to ensure that LTP was induced.

For Western analysis, five to six slices were chemically treated whereas an additional two untreated slices from the same animal served as controls. The slices from four mice with same genotype and treatment (4hydroxytomaxifen or vehicle) were pooled together for each Western blot. Slices were quickly frozen before, $10 \mathrm{~min}$ after, and $40 \mathrm{~min}$ after perfusion with high $\mathrm{K}^{+} / \mathrm{Ca}^{2+} \mathrm{ACSF}$, and CAl were isolated. These frozen CA1 slices were then transferred to microcentrifuge tubes in a dry ice/ethanol bath where they remained frozen. The tissue was thawed and homogenized with $100 \mu$ l of ice-cold $0.3 \mathrm{M}$ sucrose buffer (containing 300 mm sucrose, 10 mm Tris pH7.4, 10 mм EGTA pH7.4, 10 mm EDTA, $\mathrm{pH7.4}$, and fresh protease and phosphatase inhibitor mixtures). After centrifugation $(5000 \mathrm{rpm}, 2 \mathrm{~min})$ at $4^{\circ} \mathrm{C}$, the supernatant was centrifuged again at $45,000 \mathrm{rpm}$ for $30 \mathrm{~min}$ at $4^{\circ} \mathrm{C}$. The resulting pellet was solubilized in Triton X-100 buffer. Ten micrograms of protein each were electrophoresed on 10\% SDS-PAGE gels. Protein quantification analysis was done as described above. Percentage changes attributable to chemical treatment were calculated relative to the optical density volume of the corresponding untreated (base) protein bands within a single experiment, and statistical significance was based on six independent Western analyses.

Electrophysiology. Sagittal hippocampal slices (400 $\mu \mathrm{m}$ thick) were prepared from adult mice ( 3 to 4 months old) as described previously (Giese et al., 1998). Field EPSPs were evoked alternatively in separate pathways (control and tetanized) by stimulating the Schaffer afferent fibers with bipolar platinum electrodes. All test stimuli and tetanus pulses were $100 \mu$ s in duration and 1/2-2/3 maximal stimulation strength. LTP was induced using $100 \mathrm{~Hz} / 1 \mathrm{~s}$ and $10 \mathrm{~Hz} / 10 \mathrm{~s}$ stimulation protocols. Long-term depression (LTD) was elicited with $1 \mathrm{~Hz}$ protocol from mice aged postnatal day 14 (P14)-P17. For measurement of paired-pulse facilitation (PPF), we used different interstimulus intervals (ISIs) of 10, 20, $50,100,200$, and $400 \mathrm{~ms}$. All recordings were done using the same setup and in the same time span. ACSF was made in the presence of $1 \mu \mathrm{M}$ 4-hydroxytomaxifen or vehicle (ethanol) alone. All the chemicals used were purchased from Sigma. Results from electrophysiological experiments are reported as the percentage of baseline EPSP slopes (mean \pm SEM). Statistical comparisons were made between groups with Fisher's protected least significant difference (PLSD) $t$ tests on the last 10 min of data (averaged). Statistical comparisons were made with $n$ equalling the number of slices.

Water maze. Our Morris water maze has been described previously (Bourtchuladze et al., 1994). The mice were given two blocks [ $1 \mathrm{~h}$ intertrial interval (ITI)] of two trials every day (30 s ITI) for $7 \mathrm{~d}$, and the starting position was varied from trial to trial. Probe trials were given at training days 3, 5, and 7. During probe trials, the platform was removed, and the mice were allowed to search for it for $60 \mathrm{~s}$. For the visible platform task, the platform was marked with a visible cue (colored ball). Mice were given two blocks ( $1 \mathrm{~h} \mathrm{ITI)} \mathrm{of} \mathrm{four} \mathrm{trials} \mathrm{(30} \mathrm{s} \mathrm{ITI)} \mathrm{per} \mathrm{day,} \mathrm{using} \mathrm{a} \mathrm{fixed}$ platform position and with changes of the starting position in each new trial.

The delayed spatial win-shift eight-arm radial-maze task. This task has been described in detail previously (Floresco et al., 1997). On the first 2 maze days, mice were habituated to the maze environment. Subsequent daily training session consists of two distinct phases (A and B), separated by a 2 min delay. In the first phase (A), food-deprived animals were allowed to enter four of the eight maze arms and obtain a reward pellet (Bioserv, Frenchtown, NJ) from each arm. In the second phase (B), all eight arms were open, but only the four that were not baited in the first phase contained a reward. Therefore, to perform correctly, mice had to remember the previous location of food from phase A and then enter the new arms during phase B. Performance was gauged by calculating the percentage of total correct arm entries made during each phase (number of correct arm entered/total number of arms entered). We also analyzed the specific types of errors that animals made: within-phase errors (reentering the same arm during phase B) and across-phase errors (reentering an arm in phase B that was baited in phase A).

Mouse was allowed a maximum of $5 \mathrm{~min}$ to retrieve the four pellets during phase A and B. An arm entry was recorded when a mouse moved down the entire length of an arm and reached the food cup at the end of the arm. The latencies to reach the food cup of the first arm visited and to complete the phase also were recorded.

Statistical analysis. Western blots were analyzed with the one-sample $t$ test (mean, 100; two tail). A repeated ANOVA was used to analyze the acquisition data from the water maze data. A single-factor ANOVA was used to analyze differences between genotype and treatment for water maze probe trials, radial maze data, and for LTP/LTD induction; Post hoc comparisons (Fisher's PLSD) between groups were performed when appropriate.

\section{Results}

\section{Generation of $c N R 2 B$ transgenic mouse}

To engineer a transgenic protein that could be used to repress endogenous CaMKII/NR2B interactions in an inducible and reversible manner, we fused the NR2B carboxy terminus (8391482 aa, cNR2B) to the ligand-binding domain of a human ER with a G521R mutation $\left(\mathrm{LBD}^{\mathrm{G} 521 \mathrm{R}}\right)$. This mutant LBD does not bind estrogen and is instead regulated by the synthetic ligand tamoxifen (Kida et al., 2002). We found that administration of TAM allows the LBD ${ }^{\mathrm{G} 521 \mathrm{R}}-\mathrm{cNR} 2 \mathrm{~B}$ fusion protein to interact with its binding partner CaMKII. The $\mathrm{LBD}^{\mathrm{G} 521 \mathrm{R}}$-cNR2B fusion gene was expressed under the control of the $\alpha$ CaMKII promoter (Fig. $1 A$ ), which is known to be active only in postnatal neurons of forebrain areas, including the hippocampus, amygdala, cortex, and striatum (Mayford et al., 1996). The resulting transgenic mice bred normally and showed no overt behavioral abnormalities.

Reverse transcriptase (RT)-PCR and Western blot analyses confirmed the presence of $\mathrm{LBD}^{\mathrm{G} 521 \mathrm{R}}-\mathrm{cNR} 2 \mathrm{~B}$ messenger RNA (Fig. $1 B$ ) and protein (Fig. $1 C, D$ ) in the brain of the transgenic mice, especially in the hippocampus and cortex. Both an anti-ER (HC-20) antibody and an anti-NR2B C-terminal antibody (NR2BC) detected the LBD ${ }^{\text {G521R }}-\mathrm{cNR} 2 \mathrm{~B}$ protein $(110 \mathrm{kDa})$ in the transgenic mice (Fig. 1C,D). To induce the function of the $\mathrm{LBD}^{\mathrm{G} 521 \mathrm{R}}$-cNR2B protein, transgenic mice and their wild-type littermates were injected intraperitoneally with TAM (or an equivalent volume of DMSO; vehicle) daily for $5 \mathrm{~d}$, and killed on the fifth day, $6 \mathrm{~h}$ after the final injection. To avoid the toxic effects of DMSO, individual animals received no $>50 \mu \mathrm{l}$ of the TAM (or vehicle) solution each time they were injected. Although TAM (20 mg/kg/d for 5 consecutive days) did not affect the gross expression levels of the fusion protein in forebrain, it did affect its subcellular distribution; TAM treatment resulted in an increase in the levels of $\mathrm{LBD}^{\mathrm{G} 521 \mathrm{R}}-\mathrm{cNR} 2 \mathrm{~B}$ in the SS and PSD fractions, perhaps because the active $\mathrm{LBD}^{\mathrm{G} 521 \mathrm{R}}$-cNR2B protein, but not the inactive form, interacts with targets (i.e., CaMKII) in these fractions (Fig. $1 E$ ).

To test whether $\mathrm{LBD}^{\mathrm{G} 521 \mathrm{R}}$-cNR2B activation affects the levels of other PSD-enriched proteins, including NR1, NR2A, NR2B, and PSD-95, etc., we measured the levels of several important 
PSD proteins by Western blot analysis using forebrain PSD-enriched fractions. No significant changes were observed in the level of these proteins among the four different treatment groups (Fig. 2).

TAM-activated LBD ${ }^{\text {G521R }}$-cNR2B protein binds to CaMKII in vivo

First, we immunoprecipitated Triton X-100-solubilized CaMKII complexes from forebrain homogenates with an antibody against CaMKII (6G9). Subsequent immunoblotting of the complexes with an antibody against the ER revealed the presence of the $\mathrm{LBD}^{\mathrm{G} 521 \mathrm{R}}-\mathrm{cNR} 2 \mathrm{~B}$ protein in complexes pulled down from transgenic mice treated with TAM injection ( $\mathrm{tg} / \mathrm{tam})$, but not in the other three control groups [wt/veh, wild-type mice treated with TAM (wt/tam), and transgenic mice treated with vehicle (tg/veh)]. Conversely, immunoprecipitation of ER complexes with the same antibody against the ER resulted in the coprecipitation of CaMKII only in the TAM-treated transgenic group (supplemental Fig. 1, available at www.jneurosci. org as supplemental material). These findings mean that TAM-activated $\mathrm{LBD}^{\mathrm{G} 521 \mathrm{R}}$ cNR2B binds to CaMKII in vivo, but its inactive form does not.

Second, to test whether TAM-activated $\mathrm{LBD}^{\mathrm{G} 521 \mathrm{R}}$-cNR2B binds to CaMKII in a fraction enriched in synaptic proteins, we used 1\% Doc buffer (Robison et al., 2005a,b) to solubilize synaptosome lysates prepared from forebrain. Doc-solubilized synaptosomes were subjected to immunoprecipitation with an antibody against ER. Subsequent immunoblotting of ER complexes with antibodies against $\alpha$ CaMKII revealed coprecipitation of CaMKII only in the TAM-treated transgenic group, but not in the other three control groups (wt/veh, wt/tam, and tg/veh) (Fig. $3 A$ ). This result means that TAM-activated $\mathrm{LBD}^{\mathrm{G} 521 \mathrm{R}}-\mathrm{cNR} 2 \mathrm{~B}$ binds to synapse-associated CaMKII, but its inactive form does not.

Previous studies showed that endogenous NR2B binds to PSD-95 (Kornau et al., 1995). We therefore tested whether TAMactivated $\mathrm{LBD}^{\mathrm{G} 521 \mathrm{R}}-\mathrm{cNR} 2 \mathrm{~B}$ binds to PSD-95 in addition to CaMKII. Immunoblotting of the same ER complexes with antibodies against PSD-95 (7E3) did not detect coprecipitation of PSD-95 with the ER-labeled fusion protein in synaptosome lysates from tg/tam mice (Fig. $3 A$ ), showing that, by itself, the $\mathrm{LBD}^{\mathrm{G} 521 \mathrm{R}}$-cNR2B transgenic fragment does not bind PSD-95 stably. Neither CaMKII nor PSD-95 were coprecipitated with the fusion protein in the other three control groups.

\section{LBD $^{\text {G521R }}$-cNR2B decreases the association between CaMKII and endogenous NR2B receptor complexes}

Next, we tested whether the TAM-activated cNR2B fusion protein disrupts the association between CaMKII and endogenous NR2B receptor complexes. Doc-solubilized synaptosomes containing NR2B were immunoprecipitated with an antibody against NR2BN. Because this antibody was raised against the $\mathrm{N}$ terminus of NR2B, it can recognize the endogenous NR2B subunit $(180 \mathrm{kDa})$, but not LBD ${ }^{\mathrm{G} 521 \mathrm{R}}{ }_{-\mathrm{cNR}} \mathrm{B}(110 \mathrm{kDa})$. Immunoblots of the immunoprecipitated NR2B complexes (Fig. $3 B$ )
A
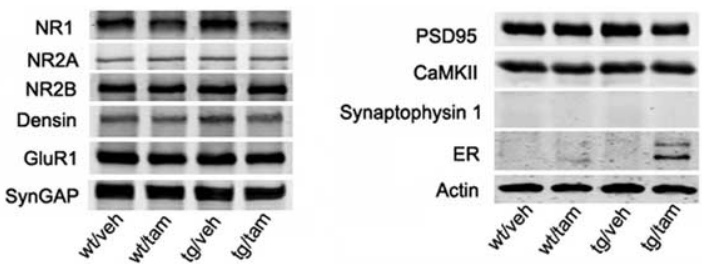

B

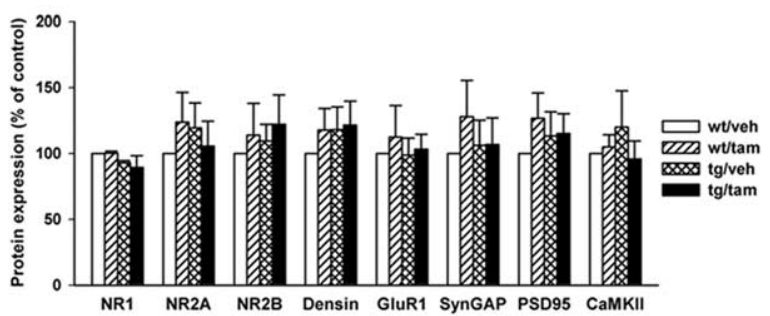

Figure 2. Activation of $L B D^{6521 R}{ }_{-}$-NR2B does not affect expression of PSD-enriched proteins. $\boldsymbol{A}$, Immunoblots of PSD fractions from transgenic and control mice with antibodies against several synaptic proteins shows that activation of $L B D^{G 521 R}{ }_{-}-N R 2 B$ does not affect the level of expression of PSD-enriched proteins, including GluR1, NR1, NR2A, NR2B, Densin-180, SynGAP, PSD-95, and CaMKII. Labeling with $\beta$-actin is used to control for protein loading. Immunoblotting with antibody against Synaptophysin 1 demonstrates that the PSD fractions are free of most presynaptic proteins. Immunoblotting with an antibody against the ER demonstrates that $L B D^{G 521 R}{ }_{-C N R 2 B}$ is detected only in PSD fractions from tg mice after TAM treatment. $\boldsymbol{B}$, For quantification, the amount of each protein is standardized as a ratio of protein/ actin. The ratio of wt/veh group is then used as a standard control (100). The ratio of other groups is normalized to wt/veh before statistical analysis and expressed as a percentage of control. Error bars represent SE in all figures.

demonstrated that the amount of $\alpha$ CaMKII coprecipitated was significantly reduced in the $\mathrm{tg} / \mathrm{tam}$ group, compared with the other three control groups ( $\mathrm{tg} / \mathrm{tam}, 77.6 \pm 7.8 \% \mathrm{of}$ wt/veh group, $p<0.01$, one-sample $t$ test, $n=6$; wt $/ \mathrm{tam}, 99.3 \pm 8.4 \%$; tg/veh, 


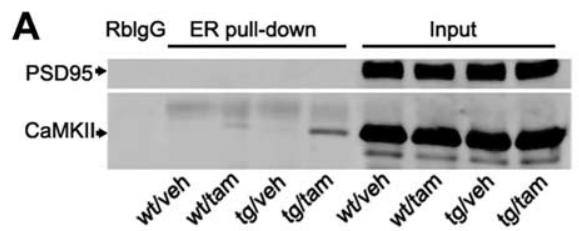

B
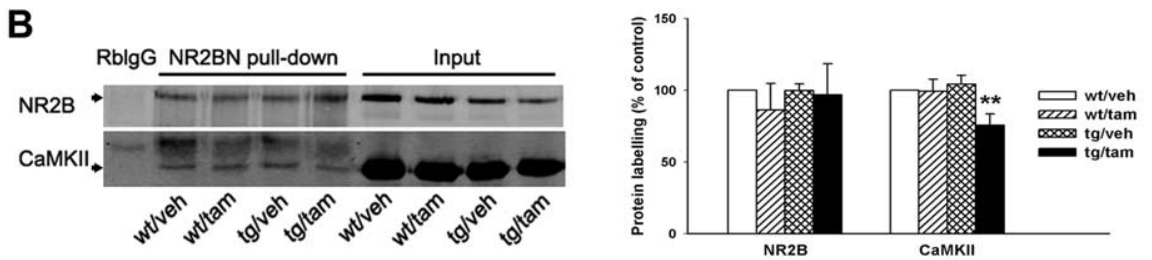

C

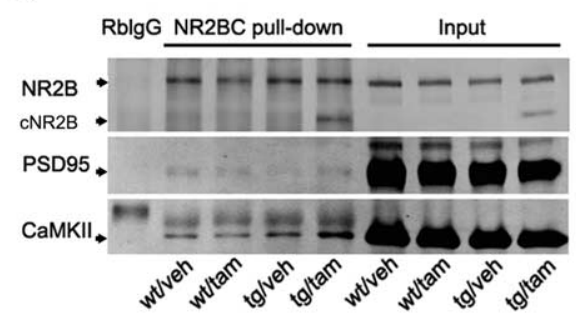

D
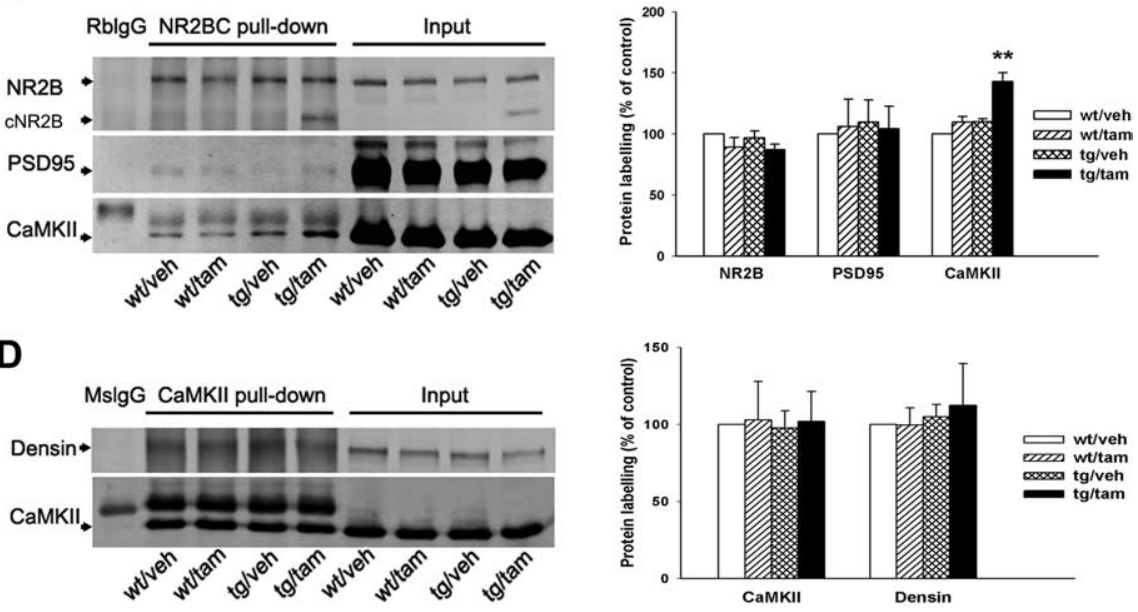

Figure 3. Coimmunoprecipitation studies show that activated $L_{B D}{ }^{G 521 R}$-cNR2B binds to CaMKII and interferes with the endogenous NR2B/CaMKII interaction, but not with the endogenous densin-180/CaMKII interaction. $\boldsymbol{A}$, Immunoblots show that activated LBD ${ }^{\text {G521R }}$-CNR2B binds significantly to CaMKII but not PSD-95. Coimmunoprecipitation is done with an ER antibody, followed by immunoblots with CaMKII and PSD-95 antibodies. B, Coimmunoprecipitation is done with NR2BN antibody. Immunoblots (left) and correlated histogram (right) demonstrate significantly reduced coprecipitation of CaMKIl in the $\mathrm{tg} / \mathrm{tam}$ group $\left({ }^{* *} p<0.01 ; n=6\right)$. The precipitation of NR2B was not different among the four groups. C, Coimmunoprecipitation is done with NR2BC antibody. Immunoblots (left) and correlated histogram (right) demonstrate that coprecipitation of CaMKII is increased in the $\mathrm{tg} / \mathrm{tam}$ group $\left({ }^{* *} p<0.01 ; n=6\right)$, whereas the coprecipitation of PSD-95 and the precipitation of endogenous NR2B are not different among the four groups. D, Coimmunoprecipitation is done with CaMKII antibody. Immunoblots (left) and correlated histogram (right) show identical coprecipitation of Densin-180 with CaMKIl in the four groups. $\boldsymbol{A}-\boldsymbol{D}$, Arrowheads indicate molecular weight markers of different proteins. RblgG and MslgG represent rabbit lgG and mouse lgG used in parallel as negative control for IP. SS lysates $(30 \mu \mathrm{g})$ were eluted simultaneously as a positive control (input) for IP.

$104.2 \pm 6.3 \%)$. Importantly, all groups showed equivalent levels of precipitated NR2B (tg/tam, $96.9 \pm 21.6 \%$; wt $/ \mathrm{tam}, 86.3 \pm$ $18.4 \%$; and $\mathrm{tg} / \mathrm{veh}, 99.7 \pm 4.9 \%$ of the wt/veh group; $n=6$ ). This result shows that the TAM-activated $\mathrm{LBD}^{\mathrm{G} 521 \mathrm{R}}$-cNR2B fusion protein, but not its inactive counterpart, can reduce the interaction between CaMKII and endogenous NR2B.

As a control, we repeated the immunoprecipitation experiments with the NR2BC antibody. Because this antibody was raised against the $\mathrm{C}$ terminus of $\mathrm{NR} 2 \mathrm{~B}$, it can recognize both the endogenous NR2B subunit and the CNR2B fusion protein. Immunoblots (Fig. $3 C$ ) demonstrated that $\alpha$ CaMKII coprecipitated with NR2B in all four treatment groups. Interestingly, more $\alpha$ CaMKII coprecipitated in the tg/tam group, compared with the three control groups (tg/tam, $142.9 \pm 7.2 \%$ of wt/veh group; $p<$ 0.01 , one-sample $t$ test; $n=6$; wt/tam, $109.6 \pm 4.6 \%$ and $\mathrm{tg} / \mathrm{veh}$, $110.1 \pm 2.3 \%$ of the $\mathrm{wt} / \mathrm{veh}$ group). In contrast, the same amount of PSD-95 coprecipitated in all treatment groups (tg/tam, $104.3 \pm 18.8 \%$; wt/tam, $106.1 \pm 22.3 \%$; and $\mathrm{tg} / \mathrm{veh}, 109.6 \pm$ $18.2 \%$ of wt/veh group). It is important to note that these results were not caused by differences in the immunoprecipitation of NR2B ( $\mathrm{tg} / \mathrm{tam}$, $87.0 \pm 4.8 \%$; wt/tam, $89.2 \pm 7.9 \%$; and $\mathrm{tg} / \mathrm{veh}, 96.7 \pm 5.8 \%$ of $\mathrm{wt} / \mathrm{veh}$ control group). As expected, both endogenous NR2B and LBD ${ }^{\text {G521R }}$-cNR2B were immunoprecipitated with the NR2BC antibody from $\mathrm{tg} / \mathrm{tam}$ samples. Together these results show that TAM-activated LBD ${ }^{\text {G521R }}$. cNR2B binds to CaMKII and interferes with its interaction with endogenous NR2B.

\section{LBD $^{\text {G521R }}{ }_{\text {-cNR2B does not alter the }}$} association between CaMKII and densin Next, we tested whether the activated $\mathrm{LBD}^{\mathrm{G} 521 \mathrm{R}}$-cNR2B also interferes with the association between CaMKII and other potential binding partners such as densin (Walikonis et al., 2001). Immunoprecipitation with the $\alpha$ CaMKII antibody and Western blot analysis with the densin-180 antibody (CT245) (Apperson et al.,1996) showed equivalent levels of densin in all four groups ( $\mathrm{tg} / \mathrm{tam}, 105.8 \pm 7.8 \%$; wt/ tam, $111.3 \pm 7.4 \%$; and $\mathrm{tg} / \mathrm{veh}, 114.9 \pm$ $16.6 \%$ of the wt/veh control group) (Fig. $3 D)$. Altogether, these results demonstrate that activation of LBD ${ }^{\text {G521R }}$-cNR2B transgenic protein reduces the binding between CaMKII and endogenous NR2B in synapses, but does not alter binding between CaMKII and densin.

\section{Activation of LBD ${ }^{\text {G521R }}$-cNR2B affects Thr286 phosphorylation of $\alpha$ CaMKII associated with PSD}

We asked whether disruption of the interaction between CaMKII and endogenous NR2B altered activity of $\alpha$ CaMKII. Because the phosphorylation of $\alpha \mathrm{CaMKII}$ at Thr286 endows $\alpha$ CaMKII with autonomous activity and plays a major role in synaptic plasticity and learning, we examined the level and Thr286 phosphorylation state of $\alpha$ CaMKII by immunoblot analysis of fractions enriched in forebrain PSDs and forebrain homogenates (Fig. 4). In the PSD-enriched fraction, $\alpha$ CaMKII autophosphorylation at Thr286 (detected with the anti-Thr286-P-CaMKII antibody) was significantly reduced specifically in the TAM-treated transgenic group (tg/tam, $57.0 \pm$ $8.3 \%$ of wt/veh group; $p<0.01$, one-sample $t$ test; $n=6$ ) (Fig. $4 A$ ) (in contrast with wt/tam, $97.4 \pm 10.8 \%$ and $\mathrm{tg} / \mathrm{ve}, 102.3 \pm$ $12.2 \%$ of wt/veh group). This difference was not observed in the forebrain homogenate S1 fraction (wt/tam, $101.6 \pm 14.5 \%$; tg/ veh, $102.1 \pm 15.1 \%$; and $\mathrm{tg} / \mathrm{tam}, 94.4 \pm 13.2 \%$ of wt/veh group; one-sample $t$ test, $p>0.05 ; n=6$ per group) (Fig. $4 B$ ). Nor were significant changes observed in the total expression level of either $\alpha$ CaMKII or $\beta$-actin (data not shown). These results indicate that induction of the LBD ${ }^{\mathrm{G} 521 \mathrm{R}}{ }_{-\mathrm{cNR}} \mathrm{BB}$ protein decreases the steady state level of activation of $\alpha$ CaMKII.

To confirm whether $\alpha$ CaMKII activity is decreased in parallel with the decreased autophosphorylation, we measured the phosphorylation of one of its key substrates, the GluR1 subunit of the 
AMPA-type glutamate receptor. Previous studies have shown that serine 831 (Ser831) of GluR1 is specifically phosphorylated by CaMKII and protein kinase C (PKC) (Roche et al., 1996; Barria et al., 1997). We found that phosphorylation of Ser831 was reduced in the PSD fraction of $\mathrm{tg} / \mathrm{tam}$ mice $(69.7 \pm 9.3 \%$ of $\mathrm{wt} / \mathrm{veh}$ group; $p<0.05$, one-sample $t$ test; $n=8$ ) (Fig. 4C), but not in forebrain homogenates (Fig. $4 D$ ). The presence or activation of $\mathrm{LBD}^{\mathrm{G} 521 \mathrm{R}}$-cNR2B did not alter the level of GluR1. These results indicate that the kinase activity of CaMKII in the PSD is reduced after induction of LBD $^{\text {G521R }}$-cNR2B.

Together, these data demonstrate that activation of the LBD ${ }^{\text {G521R }}$-cNR2B transgenic protein inhibits interaction between CaMKII and NR2B, leading to a decrease in the autophosphorylation and kinase activity of $\alpha$ CaMKII in the PSD in vivo, and to a subsequent decrease in GluR1 phosphorylation at serine 831 , a site known to be critical for the function of this receptor (Lee et al., 2003).

\section{Activation of LBD ${ }^{\text {G521R }}$-cNR2B impairs phosphorylation of $\alpha$ CaMKII at Thr286 after chemical induction of LTP}

The results presented above indicate that the continued activation of the LBD ${ }^{\mathrm{G} 521 \mathrm{R}_{-}}$ CNR2B protein can interfere with the interaction between CaMKII and NR2B and therefore decrease the basal levels of active $\alpha$ CaMKII. To determine whether the fusion protein can also interfere with the increase in autophosphorylation of $\alpha$ CaMKII after LTP, we measured autophosphorylation of Thr286 after LTP induction in transgenics and controls in the presence or absence of TAM induction. Chemical LTP was used to ensure that a very large proportion of the synapses and spines examined were potentiated, allowing for a more robust biochemical analysis. Previous studies have shown that, like tetanus-induced LTP, cLTP triggers a persistent increase in autophosphorylation of $\alpha$ CaMKII (Makhinson et al., 1999; Otmakhov et al., 2004).

Chemical LTP was induced in CA1 of acute hippocampal slices by a brief application of high $\mathrm{K}^{+} / \mathrm{Ca}^{2+}$ ACSF after FSK treatment. Immediately after FSK-treated slices were exposed to high $\mathrm{K}^{+} / \mathrm{Ca}^{2+}, \mathrm{Mg}^{2+}$-free ACSF for $5 \mathrm{~min}$, synaptic transmission was nearly abolished; however, at $10 \mathrm{~min}$ after application of high $\mathrm{K}^{+} / \mathrm{Ca}^{2+}$ ACSF, fEPSPs were dramatically potentiated $(>2$ fold of baseline). The cLTP was stable $30 \mathrm{~min}$ after induction and lasted for at least $50 \mathrm{~min}$ in all tested groups. High $\mathrm{K}^{+} / \mathrm{Ca}^{2+}$ applied for $5 \mathrm{~min}$ in the absence of FSK had no lasting effect on basal fEPSPs (supplemental Fig. 2, available at www.jneurosci.org as supplemental material). Based on this time course of cLTP observed, we used slices from wt and tg mice for immunoblot analysis before (in normal ACSF), at $10 \mathrm{~min}$, and at $40 \mathrm{~min}$ after exposure to FSK treatment followed by high $\mathrm{K}^{+} / \mathrm{Ca}^{2+}, \mathrm{Mg}^{2+}$. free ACSF. As a control, we also tested slices $10 \mathrm{~min}$ after high $\mathrm{K}^{+} / \mathrm{Ca}^{2+}$ application without FSK (high $\mathrm{K}^{+} / \mathrm{Ca}^{2+}$ only control).
B

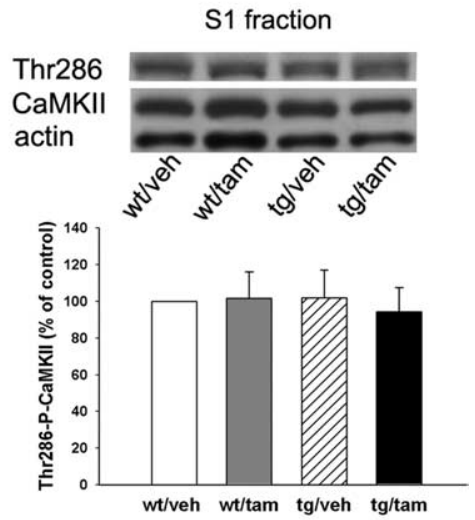

D

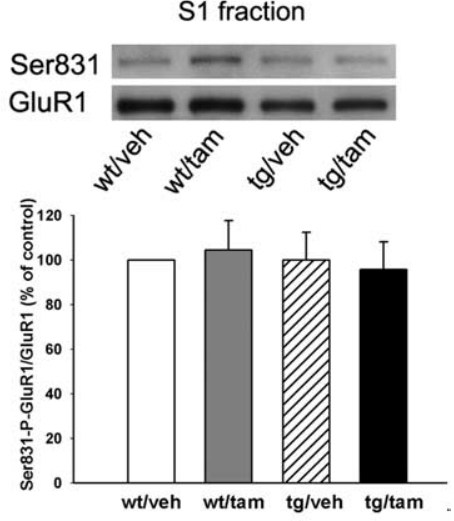

Figure 4. Thr286 autophosphorylation of $\alpha$ CaMKII and Ser831 phosphorylation of GluR1 are downregulated in the PSD fraction (PSD) of CNR2B mice. $A, B$, Representative immunoblots (top) and the quantification (bottom) of Thr286 phosphorylation of $\alpha$ CaMKIl in PSD $\left(\boldsymbol{A} ;{ }^{* *} p<0.01 ; n=6\right)$ and forebrain homogenates $S 1$ fraction $(\boldsymbol{B}) . \beta$-Actin is used as a protein loading control. (1) ratio of Thr286-P-CaMKII/actin. $C, D$, Representative Immunoblots (top) and the from other groups are normalized to it before statistical analysis. Quantifications are based on the average of $6-8$ independent experiments. Statistical analysis was done using one sample $t$ test $($ mean $=100)$.

We found that exposure of $\mathrm{tg} / \mathrm{veh}$ slices to FSK followed by high $\mathrm{K}^{+} / \mathrm{Ca}^{2+}$ produced a significant increase in autophosphorylation of $\alpha$ CaMKII at Thr286 at both $10 \mathrm{~min}(181.7 \pm 19.2 \%$ of base level; one-sample $t$ test, $p<0.01 ; n=6$ per group) and 40 $\min (141.0 \pm 13.6 \%$ of base level, one-sample $t$ test, $p<0.05 ; n=$ 6 per group) compared with that in control slices (base level, $100 \%$ ) exposed only to normal ACSF (Fig. 5). However, TAM treatment blocked the increase in phosphorylation of Thr286 observed $40 \mathrm{~min}$ after induction of cLTP in tg/tam group (95.4 \pm $14.8 \%$ of base level, one-sample $t$ test, $p>0.05 ; n=6$ ) (Fig. 5). There is no difference among the wt/tam, tg/veh and wt/veh groups $(p>0.05)$; thus, we pooled the data together for analysis (Fig. 5B, mix con). Induction of cLTP did not change the total levels of $\alpha$ CaMKII in any group (Fig. 5). The control exposed to high $\mathrm{K}^{+} / \mathrm{Ca}^{2+}$ alone did not show increases in phosphorylation of Thr286. These results demonstrate that activation of the $\mathrm{LBD}^{\mathrm{G} 521 \mathrm{R}}$-cNR2B protein blocks the long-lasting increase in phosphorylation of $\alpha$ CaMKII after cLTP induction, a result that attests to the functional importance of the interaction between the tail of NR2B and CaMKII.

\section{Deficient synaptic plasticity in the $c N R 2 B$ mice}

We asked whether activation of the $\mathrm{LBD}^{\mathrm{G} 521 \mathrm{R}}$-cNR2B, which disrupts CaMKII/NR2B interactions and subsequent autophos- 
A

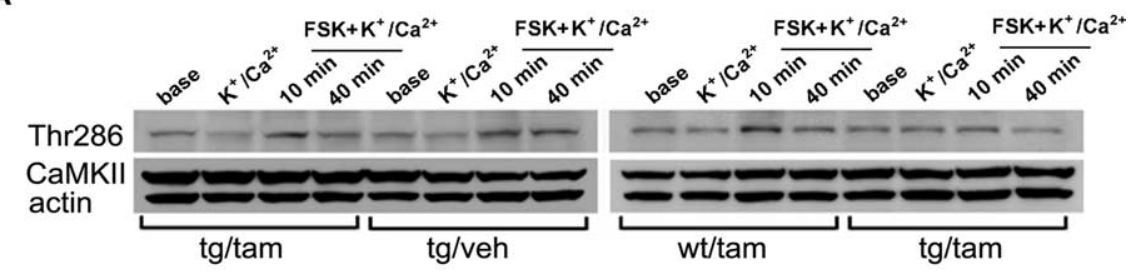

B
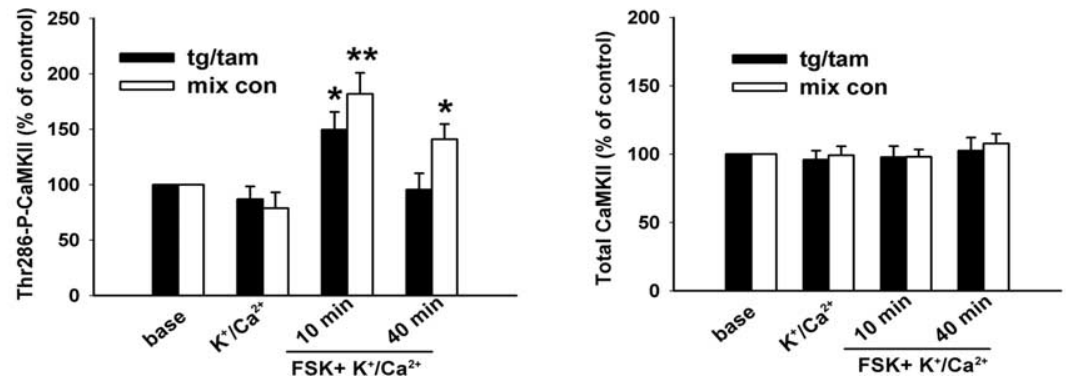

Figure 5. Time course changes in Thr286 phosphorylation of $\alpha$ CaMKII after chemical CLTP induction. $\boldsymbol{A}$, Representative immunoblots of Thr286 phosphorylation of $\alpha$ CaMKII and total CaMKIl before (base), 10 min after exposure to only high K $/ \mathrm{Ca}^{2+}$ ACSF (high $\mathrm{K}^{+} / \mathrm{Ca}^{2+}$ ), 10 min and $40 \mathrm{~min}$ after CLTP induction (FSK + high $\mathrm{K}^{+} / \mathrm{Ca}^{2+}$ ). $10 \mu \mathrm{g}$ membrane protein harvested from CA1 hippocampal slices is loaded into each lane. $\beta$-Actin is used as a protein loading control. $B$, Analyses reveal that in $\mathrm{tg} / \mathrm{tam}$ slices increases in $\alpha$ CaMKII phosphorylation at Thr286 are only observed $10 \mathrm{~min}$ after CLTP induction, whereas in controls (mix con) these increases are observed at both time points. There is no significant difference in total CaMKII expression after chemical treatment. Thr286 phosphorylation and total $\alpha$ CaMKII are measured by the ratio of Thr286-P-CaMKII/actin or the ratio of CaMKII/ actin. The ratio from base group is used as standard control (100) and ratios from other treatment groups are normalized to it before statistical analysis. Quantifications are based on the average of six independent experiments. ${ }^{*} p<0.05$ and ${ }^{* *} p<0.01$ are significant with one sample $t$ test (mean $=100$ ).

phorylation of $\alpha$ CaMKII, affects synaptic transmission, LTD or LTP in hippocampal area CA1 of adult mice. First, we looked at basal synaptic transmission by measuring fEPSPs after stimulation with a range of stimulus intensities. To control for the differential recruitment of presynaptic axons in different slices, we plotted synaptic responses against presynaptic fiber volley amplitudes. Analysis of the input-output curves from the four groups ( $w t / v e h, w t / t a m, t g / v e h$ and $\mathrm{tg} / \mathrm{tam}$ ) showed that they were indistinguishable, indicating that there are no obvious changes in basal synaptic strength. Additionally, PPF across different interstimulus ISIs revealed no differences among genotype/treatment groups (supplemental Fig. 3, available at www.jneurosci.org as supplemental material). Altogether these data suggest that, as we had expected, activation of the $\mathrm{LBD}^{\mathrm{G} 521 \mathrm{R}}{ }_{-\mathrm{cNR}} \mathrm{B}$ does not disrupt presynaptic function or basal synaptic transmission.

In contrast, activation of $\mathrm{LBD}^{\mathrm{G} 521 \mathrm{R}}$-cNR2B impaired LTP in area CA1 induced by two different patterned tetani. LTP triggered by a $100 \mathrm{~Hz}$ tetanus for $1 \mathrm{~s}$ was significantly reduced, albeit not completely absent, in hippocampal slices prepared from transgenic mice treated with TAM $(\mathrm{tg} / \mathrm{tam}, 129.1 \pm 5.3 \%$ measured 50-60 min post tetanus, $n=16$ slices, 8 mice; tg/veh, $152.9 \pm 6.8 \%$ at $50-60 \mathrm{~min}$ post, $n=16$ slices, 8 mice; wt $/$ tam, $148.2 \pm 6.8 \%$ at $50-60 \mathrm{~min}$ post, $n=16$ slices, $8 \mathrm{mice}$; $\mathrm{wt} / \mathrm{veh}$, $151.6 \pm 6.2 \%$ at $50-60 \mathrm{~min}$ post, $n=14$ slices, 7 mice; one-way ANOVA, $F_{(3,58)}=3.58$, Fisher's PLSD, $p<0.05$ ) (Fig. $6 A$ ). Similarly, a $10 \mathrm{~Hz}$ tetanus for $10 \mathrm{~s}$ also revealed significant deficit in LTP specifically in $\mathrm{tg} / \mathrm{tam}$ mice $(114.5 \pm 6.0 \%$ at $50-60 \mathrm{~min}$ post tetanus, one-way ANOVA, $F_{(3,44)}=4.02$, Fisher's PLSD, $p<$ $0.05 ; n=12$ slice, 6 mice per group), but not in other mice (tg/veh, $137.5 \pm 6.0 \%$; wt/tam, $139.6 \pm 7.3 \%$; wt/veh $139.2 \%$ $\pm 5.2 \%$ ) (Fig. $6 \mathrm{~B}$ ). These results demonstrate that the activation

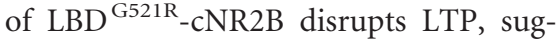
gesting that the suppression of autophosphorylation of $\alpha$ CaMKII produced by disruption of the interaction between CaMKII and the tail of NR2B is sufficient to interfere with mechanisms of LTP. In contrast with LTP, the activation of the $\mathrm{LBD}^{\mathrm{G} 521 \mathrm{R}}$-cNR2B did not affect LTD induced with a traditional 900 pulse/ $1 \mathrm{~Hz}$ stimulus in juvenile mice (Fig. 6C).

Collectively, these results indicate that activation of the $\mathrm{LBD}^{\mathrm{G} 521 \mathrm{R}}$-cNR2B causes deficits in LTP without disrupting synaptic transmission or LTD. Because autophosphorylation of $\alpha$ CaMKII at Thr286 has been shown to be critical for induction of LTP under the conditions we have used here, the simplest explanation for our findings is that a decrease in autophosphorylation of Thr286 in the PSD produced by disruption of the interaction between the tail of NR2B and CaMKII by $\mathrm{LBD}^{\mathrm{G} 521 \mathrm{R}}-\mathrm{cNR} 2 \mathrm{~B}$ prevents induction of LTP.

\section{Loss of normal CaMKII/NR2B interaction impairs spatial learning in the Morris water maze}

Mutations that disrupt CaMKII function lead to LTP impairments and spatial learning deficits in the Morris water maze task (Silva et al., 1992; Mayford et al., 1996). Training in this hippocampal-dependent task also results in the activation of CaMKII (Tan and Liang, 1996). To determine whether the activation of the $\mathrm{LBD}^{\mathrm{G} 52 \mathrm{IR}}$-cNR2B affects spatial learning, we tested the mice in the hidden-platform version of the Morris water maze, a task in which animals are trained to search for a submerged platform in a pool of water. After 3,5, and $7 \mathrm{~d}$ of training (four trials per day), spatial learning was assessed with probe trials in which the platform was removed from the pool, and the mice were allowed to search for $60 \mathrm{~s}$. In the probe trial given at day 5 , we found that $\mathrm{tg} / \mathrm{veh}, \mathrm{wt} / \mathrm{veh}$, and wt/tam mice spent significantly more time searching in the quadrant where the platform was during training (target quadrant) than in the other three quadrants. The tg/tam mice, in contrast, did not search selectively in the target quadrant (Fig. $7 B$ ). There were significant differences between $\mathrm{tg} / \mathrm{tam}$ mice and the other three groups in three different measures of spatial learning: the time spent in the target quadrant $(\mathrm{tg} / \mathrm{tam}, 24.8 \pm 3.9 \%, n=9 ; \mathrm{tg} / \mathrm{veh}, 40.8 \pm 4.3 \%$, $n=10$; wt $/ \mathrm{tam}, 45.1 \pm 4.8 \%, n=14$; wt $/ \mathrm{veh}, 42.9 \pm 5.3 \%, n=$ 8 ), the number of crossings over the location where the platform had been (tg/tam, $1.1 \pm 0.5 ; \mathrm{tg} / \mathrm{veh}, 2.8 \pm 0.7$; wt/tam, $3.1 \pm 0.7$; $\mathrm{wt} / \mathrm{veh}, 3.3 \pm 0.5)$, and proximity to the platform ( $\mathrm{tg} / \mathrm{tam}, 59.8 \pm$ $2.4 \mathrm{~cm} ; \mathrm{tg} / \mathrm{veh}, 48.3 \pm 3.5 \mathrm{~cm} ; \mathrm{wt} / \mathrm{tam}, 46.0 \pm 3.4 \mathrm{~cm}$; wt $/ \mathrm{veh}$, $43.5 \pm 3.3 \mathrm{~cm}$, one-way ANOVA, $F_{(3,37)}>3.0$, Fisher's PLSD, $p<$ 0.05 ) (Fig. $7 B-D$ ). However, extended training eliminated these deficits; analysis of the results from the probe trial given at the end of the seventh day of training show that tg/tam mice searched selectively in the target quadrant (supplemental Fig. 4, available at www.jneurosci.org as supplemental material). Escape latencies during training (repeated ANOVA, $F_{(18,222)}=0.89 ; p>0.05$ ) (Fig. 7A), and swim speed (data not shown) in each of the probe trials was not significantly different between groups, suggesting 

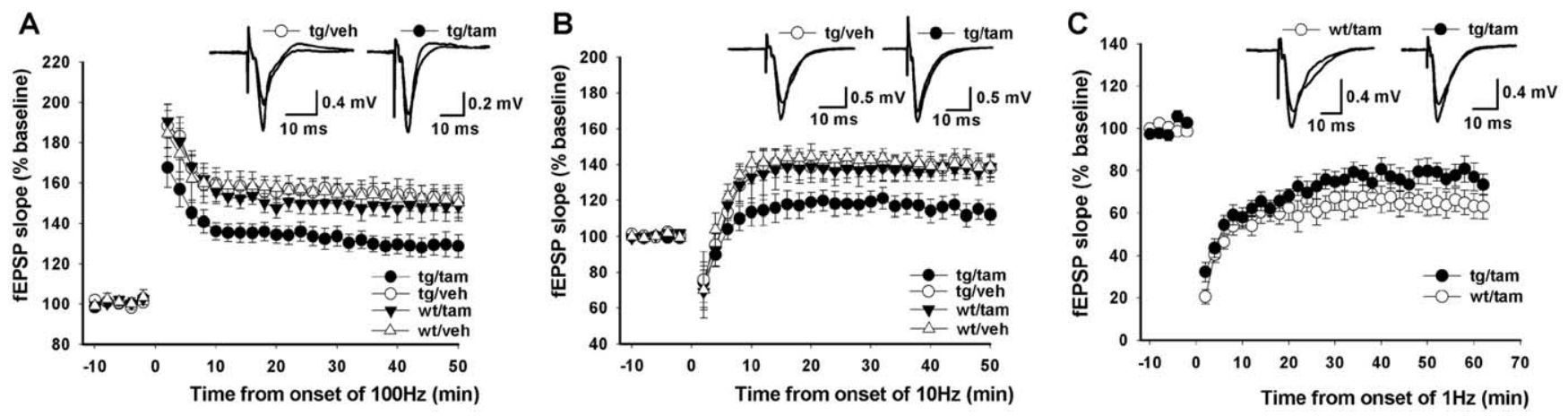

Figure 6. Reduced LTP and normal LTD in the CNR2B transgenic mice. $A, L T P$ induced with $100 \mathrm{~Hz}(1 \mathrm{~s})$ stimulation is reduced in the tg mice with tamoxifen induction compared with the other three control groups. The LTP of the other three groups is indistinguishable. $\boldsymbol{B}, \mathrm{LTP}$ induced with $10 \mathrm{~Hz}(10 \mathrm{~s})$ stimulation is also specifically reduced in the tg mice with tamoxifen induction. $\boldsymbol{C}$, LTD (1 Hz, $15 \mathrm{~min}$ ) in young tg mice (P14-P17) after tamoxifen induction is normal. Insets, Sample traces (average of five) taken at baseline and 50 - 60 min after tetanic stimulation.
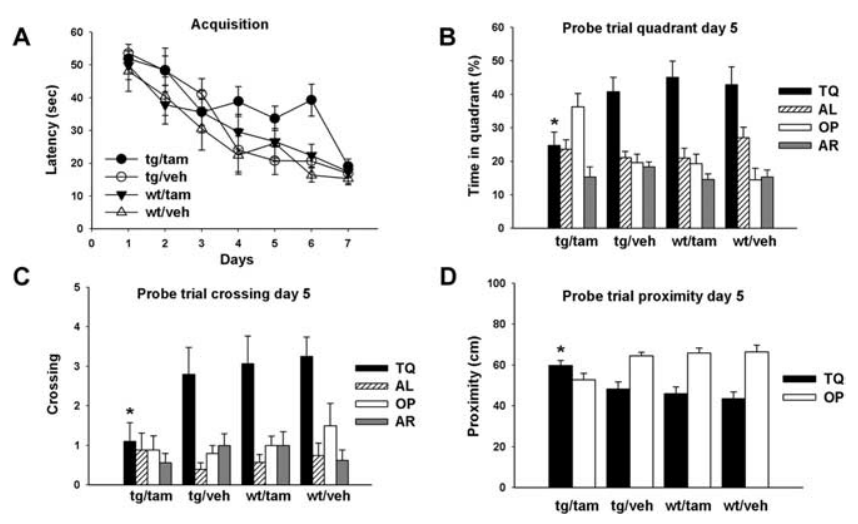

Figure 7. Tamoxifen induction reveals spatial learning deficits in the CNR2B mice. $\boldsymbol{A}$, Time to find the hidden platform plotted versus training day. $\boldsymbol{B}$, Percentage time spent in each quadrant during a probe trial on day 5 . Grouped bars from left to right indicate four different groups. Time spent in target quadrant (TQ), adjacent left quadrant (AL), opposite quadrant (OP), and adjacent right quadrant (AR) are labeled as indicated. C, Platform quadrant crossing times during the day 5 probe test. $\boldsymbol{D}$, Average proximity to the exact position where the platform is during training, compared with proximity to the opposite position in the pool. The data are analyzed from eight to 14 animals per group. ${ }^{*} p<0.05$ (one-way ANOVA followed by Fisher's PLSD) reveals learning deficits in the $\mathrm{tg} / \mathrm{tam}$ mice, but not in any of the other groups.

that the activation of the LBD ${ }^{\text {G521R }}{ }_{-} \mathrm{cNR} 2 \mathrm{~B}$ impairs spatial learning without affecting motor performance in the maze.

To ensure that the spatial learning deficit observed in $\mathrm{LBD}^{\mathrm{G} 521 \mathrm{R}}{ }_{-} \mathrm{N} N \mathrm{R} 2 \mathrm{~B}$ mice was not caused by changes in motivation, coordination or sensory processing, we tested the animals in the visible-platform task of the water maze. This is a nonspatial learning task known to be independent of hippocampal function, but with otherwise similar motivational, sensory and motor requirements. In this task, the platform is marked by a visible cue. A new group of $c N R 2 B$ transgenic and controls were trained for $4 \mathrm{~d}$ (eight trials per day) with the visible-platform on a fixed location, but with a pseudo-random start position. Both $c N R 2 B$ transgenic and WT mice performed similarly on this task and improved with training (repeated ANOVA, $F_{(9,96)}=0.44 ; p>0.05$ ) (data not shown). Together, these results indicate that impairments in spatial learning account for the Morris water maze deficits of the

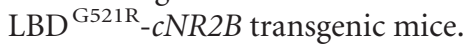

Loss of normal CaMKII/NR2B interaction impairs performance in the delayed spatial win-shift eight-arm radialmaze task

The results presented above indicate that the activation of $\mathrm{LBD}^{\mathrm{G} 521 \mathrm{R}}$-cNR2B causes deficits in spatial learning. To confirm
A

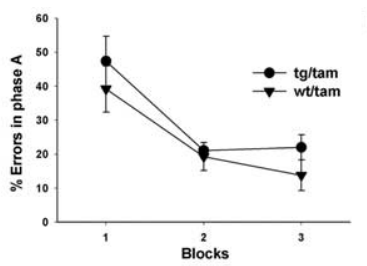

B

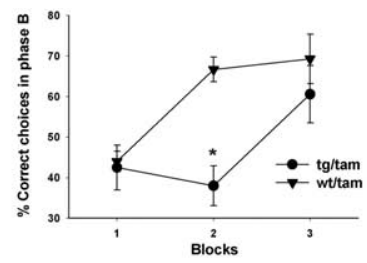

C

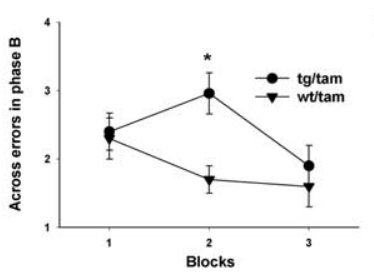

D

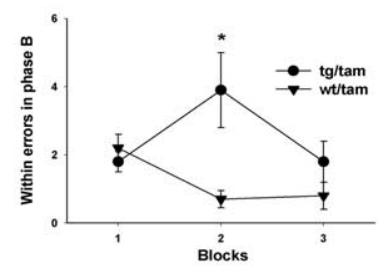

Figure 8. Learning deficits in the delayed spatial win-shift eight-arm radial-maze task. $\boldsymbol{A}$, $\mathrm{tg} / \mathrm{tam}$ mice are normal in phase $\mathrm{A}$, indicating that they are not anxious and that they do not have visual or motor deficits. $\boldsymbol{B}, \mathrm{tg} / \mathrm{tam}$ mice learn the task at significantly slower rate as indicated by a poor percentage of correct choice in block 2 of phase B. $C, \mathrm{tg} / \mathrm{tam}$ mice make significant more across errors in block 2, compared with wt/tam controls, revealing spatial memory deficits. $\boldsymbol{D}$, tg/tam mice made significant more within errors in block 2, compared with $\mathrm{wt} /$ tam controls, indicating that they may have spatial working memory deficits. Every experimental group includes $8-10$ animals. ${ }^{*} p<0.05$ (one-way ANOVA followed by Fisher's PLSD) reveals learning deficits in the $\mathrm{tg} / \mathrm{tam}$ mice.

that the activation of $\mathrm{LBD}^{\mathrm{G} 521 \mathrm{R}}$-cNR2B disrupted hippocampaldependent learning, and to further explore the nature of these deficits, we tested mice in the delayed eight-arm radial-maze task, which is a spatial working memory test that exploits rodents' innate foraging behavior. Previous studies have shown that lesions or inactivations of the hippocampal formation (Olton et al., 1978; Floresco et al., 1997) cause severe impairments on this spatial task.

All four groups of mice (wt/veh, wt/tam, tg/veh, and tg/tam, eight to 10 mice per group) received 9 consecutive days of training. We averaged data collected from three consecutive days from each mouse as one block, and used these blocks for the final comparison among groups. There was no significant difference between groups in the percentage of total errors made on phase $\mathrm{A}$ across training days (repeated ANOVA, $F_{(6,62)}=0.45 ; p>0.05$ ) (Fig. $8 \mathrm{~A}$ ). Analysis of the phase $\mathrm{B}$ results showed that during the first block (days 1-3), all groups performed at chance level. During the second block (days 4-6), control mice showed improvement and reached asymptotic performance. In contrast, analyses of the tg/tam group data revealed that these mice showed no improvement in the percentage of correct choices between blocks 1 and $2\left(F_{(3,31)}=6.4\right.$; Fisher's PLSD, $\left.p<0.05\right)$ (Fig. $\left.8 B\right)$. When 
we examined the types of errors made during the second testing block, we found that the tg/tam mice made more across-phase errors (across error; $F_{(3,31)}=3.4 ; p<0.05$ ) (Fig. $8 C$ ) and more within-phase errors (within error; $F_{(3,31)}=6.1 ; p<0.05$ ) (Fig. $8 D$ ) than the other three groups of control mice. However, just as in the water maze, extended training remediated these deficits. In the third block of testing (days 7-9), the performance of $\mathrm{tg} / \mathrm{tam}$ mice, measured as percentage of correct choices, across and within errors, was indistinguishable from the others $\left(F_{(3,31)}<1.0\right.$; $p>0.05$ ) (Fig. $8 B-D$ ). There were no significant differences among the groups in the latencies to reach the first food cup or in the average time per subsequent choice of arms on either the training or the test phases of the daily trials $\left(F_{(3,31)}<1.0 ; p>\right.$ 0.05).

After all four groups reached criterion performance (all four pellets were retrieved in five or fewer choices during phase B for 2 consecutive days), we increased the interphase interval to 20,60, or 150 min randomly. Statistical analysis revealed an overall significant effect of delay (repeated ANOVA, $F_{(3,42)}>3.0 ; p<0.05$ ). However, there was no significant effect of genotype/treatment or an interaction between genotype/treatment and delay (repeated ANOVA, $\left.F_{(3,42)}<1.0 ; p>0.05\right)$. The performance of all four groups decreased in the same manner and fell to chance level at the 150 min delay. This suggests that transgenic mice do not forget which arms were visited during phase A more quickly than WT animals.

Next, we examined whether the deficits described above were caused by impairments in spatial learning or to difficulties in acquiring the win-shift rule. To do this we tested the same groups of mice in a different environment (with distinct room cues but the same win-shift rules). Although both groups of mice took a shorter time ( $6 \mathrm{~d})$ to achieve the previous criterion performance, the overall performance of the mice was similar in both mazes. Once again the $\mathrm{tg} / \mathrm{tam}$ mice were slower to acquire the task and showed a reduction in the percentage of correct choices $\left(F_{(1,20)}=\right.$ 8.2; PLSD, $p<0.01)$. They also made more across errors $\left(F_{(1,20)}\right.$ $=9.4 ;$ PLSD,$p<0.01)$ than control groups in the second block of testing (data not shown). This result suggests that deficits described for the $c N R 2 B$ transgenic mice are unlikely to be caused by impairments in either working memory or rule learning; instead they are likely attributable to problems with developing and using a spatial map of the environment. Once a map is formed, their performance in the maze is normal. These results are consistent with the water maze findings and they indicate that the induction of $\mathrm{LBD}^{\mathrm{G} 521 \mathrm{R}}$-cNR2B impairs the initial acquisition of spatial information.

\section{Discussion}

Here we have shown that in the adult hippocampus, interactions with the c-terminal tail of NR2B help to modulate key posttranslational synaptic events in the induction of LTP, including the autophosphorylation of $\alpha$ CaMKII and phosphorylation of GluR1. Our study also provides the first evidence that the association between CaMKII and NR2B affects the rate of acquisition of hippocampal-dependent spatial learning.

A key tool used in the present study is an inducible system in a transgenic mouse that allowed us to interfere with NR2B interactions in a temporal and neuron-specific manner. In our mice, the transgenic fusion protein $\mathrm{LBD}^{\mathrm{G521R}}-\mathrm{cNR} 2 \mathrm{~B}$ is highly expressed in forebrain regions, especially in the hippocampus, a structure important for spatial learning. Because it lacks a transmembrane domain, LBD ${ }^{\mathrm{G}^{2} 21 \mathrm{R}}$-cNR2B diffuses freely in neuronal cytosol, as demonstrated by immunoblot analysis. We have shown that in- jection of TAM, the activator of the transgenic protein, specifically activates the binding function of $\mathrm{LBD}^{\mathrm{G} 521 \mathrm{R}}-\mathrm{cNR} 2 \mathrm{~B}$ without other systemic effects on the mouse brain. First, CaMKII binds to $\mathrm{LBD}^{\mathrm{G521R}}$-cNR2B and reduces the association of CaMKII with endogenous full-length NR2B only after application of TAM. Second, after TAM administration $\mathrm{LBD}^{\mathrm{G} 521 \mathrm{R}}{ }_{-\mathrm{cNR}} \mathrm{B}$ concentrates in the PSD fraction where it competes with endogenous NR2B for binding with CaMKII. Third, TAM administration does not affect the levels of other PSD-enriched proteins, including NR1, NR2A, NR2B and PSD-95. Fourth, induction by TAM also interferes with the autophosphorylation of PSD-associated $\alpha$ CaMKII and subsequent phosphorylation of GluR1 in the PSD fraction. Finally, the inducible disruption of the biochemical events listed above leads to impaired hippocampal synaptic plasticity and consequently to deficits in hippocampal-dependent

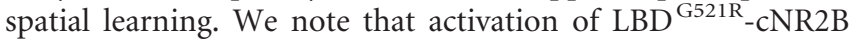
blocks only $\sim 25 \%$ of the NR2B/CaMKII interaction (Fig. $3 B$ ). This incomplete block could be a reason why LTP and learning were not completely blocked. The fact that a $25 \%$ decrease in the NR2B/CaMKII interaction has such a pronounced impact on LTP and learning attests to the importance of the NR2B/CaMKII interaction and motivated our study of its effects on learning.

The autophosphorylation of $\alpha$ CaMKII at Thr286 is postulated to play a major role in synaptic plasticity and learning, including spatial learning (Mayford et al., 1996; Giese et al., 1998; Irvine et al., 2005, 2006). This autophosphorylation is also critical for contextual fear conditioning: training in this task increases autophosphorylation of $\alpha$ CaMKII at Thr286 in spines in the lateral amygdala (LA), whereas blockade of activation of CaMKII impairs both synaptic plasticity and fear conditioning in the LA (Rodrigues et al., 2004). Tetanic (Ouyang et al., 1997, 1999; Lengyel et al., 2004) or chemically (Makhinson et al., 1999; Lengyel et al., 2004) induced LTP in area CA1 results in longlasting increases in autophosphorylation of $\alpha$ CaMKII (Lengyel et al., 2004). These findings suggest that a long-lasting increase in Thr286 autophosphorylations required for the full induction of LTP and learning.

In our present study, we examined both basal expression and dynamic changes in phosphorylation of Thr286 after induction of LTP in $c N R 2 B$ transgenic mice and in wild-type littermates. We found that activation of the $\mathrm{CNR} 2 \mathrm{~B}$ transgenic protein results in the downregulation of the basal autophosphorylation of $\alpha$ CaMKII. Interestingly, the decrease in $\alpha$ CaMKII autophosphorylation after activation of the transgenic protein was only observed in the synaptosome fraction, but not in forebrain homogenates, suggesting that the impaired autophosphorylation of $\alpha$ CaMKII observed in PSD is not simply attributable to sterical hinderance after active cNR2B binding to CaMKII, but rather to disruption of NR2B interactions in the PSD. Although PSD-95 is known to bind to endogenous NR2B receptors (Kornau et al., 1995), PSD-95 is unlikely to be the target of the transgenic cNR2B fragment in the PSD because our studies did not show significant binding between the activated fusion protein and PSD-95. However, considering that under our IP conditions, the association between endogenous NR2B with PSD-95 does not seem to be as strong as that with CaMKII (Fig. 3C), the present results may not exclude the possibility that LBD ${ }^{\text {G521R }}$-cNR2B binds to PSD-95 in vivo. Nevertheless, they do suggest that under certain conditions, TAM-activated LBD ${ }^{\text {G521R }}$-cNR2B has a more stable association with CaMKII. The molecular mechanism mediating LBD ${ }^{\text {G521R }}$ cNR2B translocation to the PSD fraction, where it competes with endogenous NR2B for binding with CaMKII, still needs to be identified. 
Consistent with previous studies (Makhinson et al., 1999; Lengyel et al., 2004; Otmakhov et al., 2004), we also found that in wt mice, cLTP leads to a persistent increase $(>40 \mathrm{~min}$ after treatment) in the Thr286 autophosphorylation of membraneassociated $\alpha \mathrm{CaMKII}$ in CA1; however, activation of the cNR2B transgenic protein, and subsequent disruption of CaMKII/NR2B interactions impair the stability of Thr286 autophosphorylation triggered by cLTP induction. Therefore, our results indicate that binding to NR2B is critical to stabilize $\alpha$ CaMKII Thr286 phosphorylation in the PSD. Accordingly, we found that activation of the cNR2B transgenic protein dampened the amplitude of CA1 LTP and impaired hippocampal-dependent spatial learning.

There is considerable evidence that synaptic activity causes CaMKII to translocate from the dendritic cytoplasm to the synapse both in vitro and in vivo (Strack et al., 1997; Shen and Meyer, 1999; Gleason et al., 2003). Targeting of CaMKII to the PSD is required for effective phosphorylation of its membrane substrates, including the GluR1 subunit of the AMPA channel (Tsui et al., 2005), whose modulation is critical for synaptic plasticity. Notably, previous studies further demonstrated that CaMKII translocation to synapses is more persistent after LTP induction (Ouyang et al., 1997, 1999; Miller et al., 2002; Otmakhov et al., 2004). The available evidence suggests two mechanisms that may determine whether translocation is persistent or transient: T286 autophosphorylation (Lengyel et al., 2004) and binding to PSD proteins, such as NR2B (Bayer et al., 2001, 2006).

Compared with recent studies from organotypic hippocampal slices demonstrating that the association between NR2B and active CaMKII is required for LTP (Barria and Malinow, 2005), our studies provide in vivo evidence that interaction with NR2B may facilitate T286 autophosphorylation (Bayer et al., 2001, 2006). Because NR2A is the principal NR2 subunit in the adult hippocampus (Sheng et al., 1994), sufficient $\mathrm{Ca}^{2+}$ entry to produce LTP may require activation of the dominant NR2 species (NR2A), but modulation of downstream events may require NR2B. Synaptic inclusion of the NR2B subunit, as either NR2B/ NR1 or NR2A/NR2B/NR1 heteromeric channels (Sheng et al., 1994), may be critical for the stabilization of long-lasting increases in Thr286 phosphorylation of $\alpha$ CaMKII in the PSD, and consequently for LTP induction and learning.

NR2B has also been previously proposed to be an important PSD docking site for CaMKII (Leonard et al., 1999; Bayer et al., 2001). Hence, it is surprising that the activation of the transgenic protein, which we showed affects the interaction between CaMKII and NR2B, did not alter the levels of total CaMKII in the PSD. Nevertheless, CaMKII interactions with other PSD proteins (including Densin-180) appear unaltered in the $c N R 2 B$ mice, and because CaMKII is expressed at high basal levels in the PSD, small decreases in these levels, caused by interfering with CaMKII/ NR2B interactions, may not be easily detectable by immunoblotting. An alternative and more likely interpretation is that in spines of $c N R 2 B$ mice, CaMKII holoenzymes still remain associated with the PSD without association with NR2B and are, thus, copurified with the PSD during our biochemical fractionation. This scenario implies that the CaMKII holoenzymes that copurify with the PSD fraction in the TAM-treated $c N R 2 B$ mice are positioned differently than in controls because of the deficit in association with the endogenous NR2B receptor. This difference could explain the reduced CaMKII autophosphorylation and reduced AMPA receptor phosphorylation.

Together, the data presented here indicate that the interaction between CaMKII and NR2B-containing NMDA receptors plays a crucial role in synaptic plasticity and spatial learning.

\section{References}

Apperson ML, Moon IS, Kennedy MB (1996) Characterization of densin180 , a new brain-specific synaptic protein of the $O$-sialoglycoprotein family. J Neurosci 16:6839-6852.

Barria A, Malinow R (2005) NMDA receptor subunit composition controls synaptic plasticity by regulating binding to CaMKII. Neuron 48:289-301.

Barria A, Muller D, Derkach V, Griffith LC, Soderling TR (1997) Regulatory phosphorylation of AMPA-type glutamate receptors by CaM-KII during long-term potentiation. Science 276:2042-2045.

Bayer KU, De Koninck P, Leonard AS, Hell JW, Schulman H (2001) Interaction with the NMDA receptor locks CaMKII in an active conformation. Nature 411:801-805.

Bayer KU, LeBel E, McDonald GL, O’Leary H, Schulman H, De Koninck P (2006) Transition from reversible to persistent binding of CaMKII to postsynaptic sites and NR2B. J Neurosci 26:1164-1174.

Berberich S, Punnakkal P, Jensen V, Pawlak V, Seeburg PH, Hvalby O, Kohr G (2005) Lack of NMDA receptor subtype selectivity for hippocampal long-term potentiation. J Neurosci 25:6907-6910.

Bourtchuladze R, Frenguelli B, Blendy J, Cioffi D, Schutz G, Silva AJ (1994) Deficient long-term memory in mice with a targeted mutation of the cAMP-responsive element-binding protein. Cell 79:59-68.

Cull-Candy S, Brickley S, Farrant M (2001) NMDA receptor subunits: diversity, development and disease. Curr Opin Neurobiol 11:327-335.

Dunkley PR, Heath JW, Harrison SM, Jarvie PE, Glenfield PJ, Rostas JA (1988) A rapid Percoll gradient procedure for isolation of synaptosomes directly from an S1 fraction: homogeneity and morphology of subcellular fractions. Brain Res 441:59-71.

Floresco SB, Seamans JK, Phillips AG (1997) Selective roles for hippocampal, prefrontal cortical, and ventral striatal circuits in radial-arm maze tasks with or without a delay. J Neurosci 17:1880-1890.

Fox CJ, Russell KI, Wang YT, Christie BR (2006) Contribution of NR2A and NR2B NMDA subunits to bidirectional synaptic plasticity in the hippocampus in vivo. Hippocampus 16:907-915.

Giese KP, Fedorov NB, Filipkowski RK, Silva AJ (1998) Autophosphorylation at Thr286 of the alpha calcium-calmodulin kinase II in LTP and learning. Science 279:870-873.

Gleason MR, Higashijima S, Dallman J, Liu K, Mandel G, Fetcho JR (2003) Translocation of CaM kinase II to synaptic sites in vivo. Nat Neurosci 6:217-218.

Irvine EE, Vernon J, Giese KP (2005) AlphaCaMKII autophosphorylation contributes to rapid learning but is not necessary for memory. Nat Neurosci 8:411-412.

Irvine EE, von Hertzen LS, Plattner F, Giese KP (2006) alphaCaMKII autophosphorylation: a fast track to memory. Trends Neurosci 29:459-465.

Kennedy MB (2000) Signal-processing machines at the postsynaptic density. Science 290:750-754.

Kennedy MB, Beale HC, Carlisle HJ, Washburn LR (2005) Integration of biochemical signalling in spines. Nat Rev Neurosci 6:423-434.

Kida S, Josselyn SA, de Ortiz SP, Kogan JH, Chevere I, Masushige S, Silva AJ (2002) CREB required for the stability of new and reactivated fear memories. Nat Neurosci 5:348-355.

Kim MJ, Dunah AW, Wang YT, Sheng M (2005) Differential roles of NR2Aand NR2B-containing NMDA receptors in Ras-ERK signaling and AMPA receptor trafficking. Neuron 46:745-760.

Kiyama Y, Manabe T, Sakimura K, Kawakami F, Mori H, Mishina M (1998) Increased thresholds for long-term potentiation and contextual learning in mice lacking the NMDA-type glutamate receptor $\varepsilon 1$ subunit. J Neurosci 18:6704-6712.

Kohr G, Jensen V, Koester HJ, Mihaljevic AL, Utvik JK, Kvello A, Ottersen OP, Seeburg PH, Sprengel R, Hvalby O (2003) Intracellular domains of NMDA receptor subtypes are determinants for long-term potentiation induction. J Neurosci 23:10791-10799.

Kornau HC, Schenker LT, Kennedy MB, Seeburg PH (1995) Domain interaction between NMDA receptor subunits and the postsynaptic density protein PSD-95. Science 269:1737-1740.

Lee HK, Takamiya K, Han JS, Man H, Kim CH, Rumbaugh G, Yu S, Ding L, He C, Petralia RS, Wenthold RJ, Gallagher M, Huganir RL (2003) Phosphorylation of the AMPA receptor GluR1 subunit is required for synaptic plasticity and retention of spatial memory. Cell 112:631-643.

Lengyel I, Voss K, Cammarota M, Bradshaw K, Brent V, Murphy KP, Giese KP, Rostas JA, Bliss TV (2004) Autonomous activity of CaMKII is only 
transiently increased following the induction of long-term potentiation in the rat hippocampus. Eur J Neurosci 20:3063-3072.

Leonard AS, Lim IA, Hemsworth DE, Horne MC, Hell JW (1999) Calcium/ calmodulin-dependent protein kinase II is associated with the N-methylD-aspartate receptor. Proc Natl Acad Sci USA 96:3239-3244.

Lisman J, Schulman H, Cline H (2002) The molecular basis of CaMKII function in synaptic and behavioural memory. Nat Rev Neurosci 3:175-190.

Lledo PM, Hjelmstad GO, Mukherji S, Soderling TR, Malenka RC, Nicoll RA (1995) Calcium/calmodulin-dependent kinase II and long-term potentiation enhance synaptic transmission by the same mechanism. Proc Natl Acad Sci USA 92:11175-11179.

Makhinson M, Chotiner JK, Watson JB, O’Dell TJ (1999) Adenylyl cyclase activation modulates activity-dependent changes in synaptic strength and $\mathrm{Ca}^{2+} /$ calmodulin-dependent kinase II autophosphorylation. J Neurosci 19:2500-2510.

Mayford M, Bach ME, Huang YY, Wang L, Hawkins RD, Kandel ER (1996) Control of memory formation through regulated expression of a CaMKII transgene. Science 274:1678-1683.

Miller S, Yasuda M, Coats JK, Jones Y, Martone ME, Mayford M (2002) Disruption of dendritic translation of CaMKIIalpha impairs stabilization of synaptic plasticity and memory consolidation. Neuron 36:507-519.

Monyer H, Burnashev N, Laurie DJ, Sakmann B, Seeburg PH (1994) Developmental and regional expression in the rat brain and functional properties of four NMDA receptors. Neuron 12:529-540.

Olton DS, Walker JA, Gage FH (1978) Hippocampal connections and spatial discrimination. Brain Res 139:295-308.

Otmakhov N, Tao-Cheng JH, Carpenter S, Asrican B, Dosemeci A, Reese TS, Lisman J (2004) Persistent accumulation of calcium/calmodulindependent protein kinase II in dendritic spines after induction of NMDA receptor-dependent chemical long-term potentiation. J Neurosci 24:9324-9331.

Ouyang Y, Kantor D, Harris KM, Schuman EM, Kennedy MB (1997) Visualization of the distribution of autophosphorylated calcium/calmodulindependent protein kinase II after tetanic stimulation in the CA1 area of the hippocampus. J Neurosci 17:5416-5427.

Ouyang Y, Rosenstein A, Kreiman G, Schuman EM, Kennedy MB (1999) Tetanic stimulation leads to increased accumulation of $\mathrm{Ca}^{2+} /$ calmodulin-dependent protein kinase II via dendritic protein synthesis in hippocampal neurons. J Neurosci 19:7823-7833.

Pettit DL, Perlman S, Malinow R (1994) Potentiated transmission and prevention of further LTP by increased CaMKII activity in postsynaptic hippocampal slice neurons. Science 266:1881-1885.

Prybylowski K, Wenthold RJ (2004) N-Methyl-D-aspartate receptors: subunit assembly and trafficking to the synapse. J Biol Chem 279:9673-9676.

Robison AJ, Bartlett RK, Bass MA, Colbran RJ (2005a) Differential modulation of $\mathrm{Ca}^{2+} /$ calmodulin-dependent protein kinase II activity by regulated interactions with N-methyl-D-aspartate receptor NR2B subunits and alpha-actinin. J Biol Chem 280:39316-39323.

Robison AJ, Bass MA, Jiao Y, MacMillan LB, Carmody LC, Bartlett RK, Colbran RJ (2005b) Multivalent interactions of calcium/calmodulindependent protein kinase II with the postsynaptic density proteins NR2B, densin-180, and alpha-actinin-2. J Biol Chem 280:35329-35336.

Roche KW, O’Brien RJ, Mammen AL, Bernhardt J, Huganir RL (1996) Characterization of multiple phosphorylation sites on the AMPA receptor GluR1 subunit. Neuron 16:1179-1188.
Rodrigues SM, Schafe GE, LeDoux JE (2001) Intra-amygdala blockade of the NR2B subunit of the NMDA receptor disrupts the acquisition but not the expression of fear conditioning. J Neurosci 21:6889-6896.

Rodrigues SM, Farb CR, Bauer EP, LeDoux JE, Schafe GE (2004) Pavlovian fear conditioning regulates Thr286 autophosphorylation of $\mathrm{Ca}^{2+}$ / calmodulin-dependent protein kinase II at lateral amygdala synapses. J Neurosci 24:3281-3288.

Sakimura K, Kutsuwada T, Ito I, Manabe T, Takayama C, Kushiya E, Yagi T, Aizawa S, Inoue Y, Sugiyama H, Mishina M (1995) Reduced hippocampal LTP and spatial learning in mice lacking NMDA receptor epsilon 1 subunit. Nature 373:151-155.

Shen K, Meyer T (1999) Dynamic control of CaMKII translocation and localization in hippocampal neurons by NMDA receptor stimulation. Science 284:162-166.

Sheng M, Cummings J, Roldan LA, Jan YN, Jan LY (1994) Changing subunit composition of heteromeric NMDA receptors during development of rat cortex. Nature 368:144-147.

Silva AJ, Paylor R, Wehner JM, Tonegawa S (1992) Impaired spatial learning in alpha-calcium-calmodulin kinase II mutant mice. Science 257:206-211.

Strack S, Colbran RJ (1998) Autophosphorylation-dependent targeting of calcium/calmodulin-dependent protein kinase II by the NR2B subunit of the N-methyl-D-aspartate receptor. J Biol Chem 273:20689-20692.

Strack S, Choi S, Lovinger DM, Colbran RJ (1997) Translocation of autophosphorylated calcium/calmodulin-dependent protein kinase II to the postsynaptic density. J Biol Chem 272:13467-13470.

Strack S, McNeill RB, Colbran RJ (2000) Mechanism and regulation of calcium/calmodulin-dependent protein kinase II targeting to the NR2B subunit of the N-methyl-D-aspartate receptor. J Biol Chem 275:23798-23806.

Tan SE, Liang KC (1996) Spatial learning alters hippocampal calcium/ calmodulin-dependent protein kinase II activity in rats. Brain Res 711:234-240.

Tang YP, Shimizu E, Dube GR, Rampon C, Kerchner GA, Zhuo M, Liu G, Tsien JZ (1999) Genetic enhancement of learning and memory in mice. Nature 401:63-69.

Thomas GM, Huganir RL (2004) MAPK cascade signalling and synaptic plasticity. Nat Rev Neurosci 5:173-183.

Tsui J, Inagaki M, Schulman H (2005) Calcium/calmodulin-dependent protein kinase II (CaMKII) localization acts in concert with substrate targeting to create spatial restriction for phosphorylation. J Biol Chem 280:9210-9216.

Walikonis RS, Oguni A, Khorosheva EM, Jeng CJ, Asuncion FJ, Kennedy MB (2001) Densin-180 forms a ternary complex with the $\alpha$-subunit of $\mathrm{Ca}^{2+}$ / calmodulin-dependent protein kinase II and $\alpha$-actinin. J Neurosci 21:423-433.

Weitlauf C, Honse Y, Auberson YP, Mishina M, Lovinger DM, Winder DG (2005) Activation of NR2A-containing NMDA receptors is not obligatory for NMDA receptor-dependent long-term potentiation. J Neurosci 25:8386-8390.

Zhao MG, Toyoda H, Lee YS, Wu LJ, Ko SW, Zhang XH, Jia Y, Shum F, Xu H, Li BM, Kaang BK, Zhuo M (2005) Roles of NMDA NR2B subtype receptor in prefrontal long-term potentiation and contextual fear memory. Neuron 47:859-872. 